\title{
The Effects of Right/Left Temporal Lobe Lesions on the Recognition of Familiar Faces
}

\author{
Guido Gainotti, Monica Ferraccioli and Camillo Marra \\ Center for Neuropsychological Research, Dept. of Neurosciences, \\ Catholic University of Rome, \\ Italy
}

\section{Introduction}

Recognition of familiar people can be based on three main sources of information: the face, the voice and the name, but the face has usually the greatest impact on this important social skill.

For this reason the study of 'prosopagnosia', considered as a form of visual agnosia, specifically concerning the recognition of familiar people through their face, has represented, since the proposal of this term by Bodamer (1947), the dominant and almost exclusive line of research in this field of inquiry. For the same reason, the first cognitive model that has tried to analyse the cognitive and subjective/behavioural stages involved in recognition and identification of familiar people is the Bruce et Young's (1986) model of familiar faces recognition. The first cognitive step of this model is the formation of a view independent structural description of a seen face, which can be compared with all the known faces stored in the Face Recognition Units (FRUs). A similar process was afterwards hypothesized for other sources of person recognition, such as voices and names, by several authors (Brédart et al., 1995; Burton et al., 1990; Burton et al., 1999; Valentine et al., 1996; Young \& Burton, 1999), who assumed that the outcome of the corresponding perceptual processing could be matched with information stored in correlative Voice (VRUs) or Name Recognition Units (NRUs). According to all these models, the second step of the people identification process requires the convergence of information stored in these modalityspecific units into person-identity nodes (PINs), allowing identification of a particular person and retrieval of the corresponding semantic (biographical) information. The PINs (or the accessed person-specific knowledge) could, in turn, activate the phonological codes underlying the production of the person's proper name.

In spite of the general similarities existing among the model proposed by Bruce and Young (1986) and those offered by following authors, there are also important differences among these models, which concern the locus in which familiarity feelings for the addressed person are generated and in which person-specific information is stored. As for the first point, the Bruce and Young (1986) model assumed that familiarity feelings are generated in the modality-specific recognition units where (for instance) the structural description of a seen face is compared to the familiar faces stored in the FRUs. On the contrary, in the Burton et 
al. (1990, 1999), Brédart et al. (1995) and Valentine et al. (1996) models, decisions about familiarity are taken at a supra-modal level, namely the PINs, where information from different modalities is combined in person identity nodes. Furthermore, the Bruce and Young's (1986) model assumes that PINs store semantic information, whereas Burton et al. (1990, 1999), Brédart et al. (1995) and Valentine et al. (1996) maintain that PINs do not store semantic information, but provide a modality-free gateway to a single semantic system, where information about people is stored in an amodal format.

Bruce \& Young's (1986) model

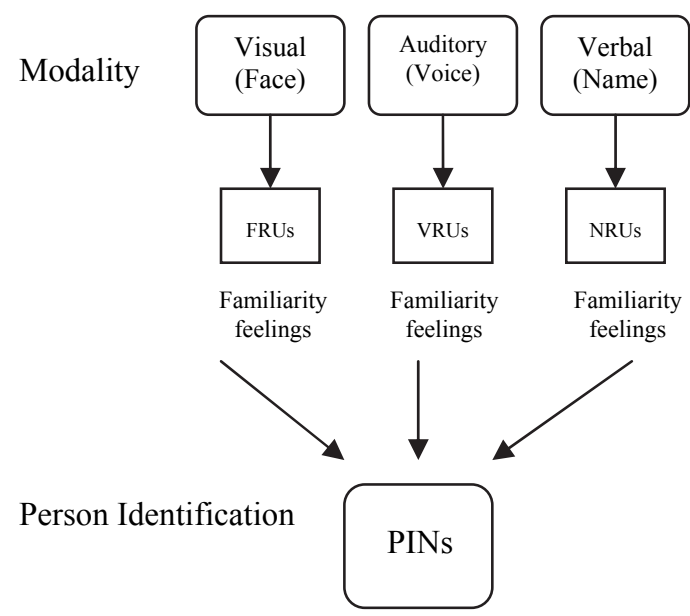

(Store of the person-specific semantic information)
Burton et al's (1990) model

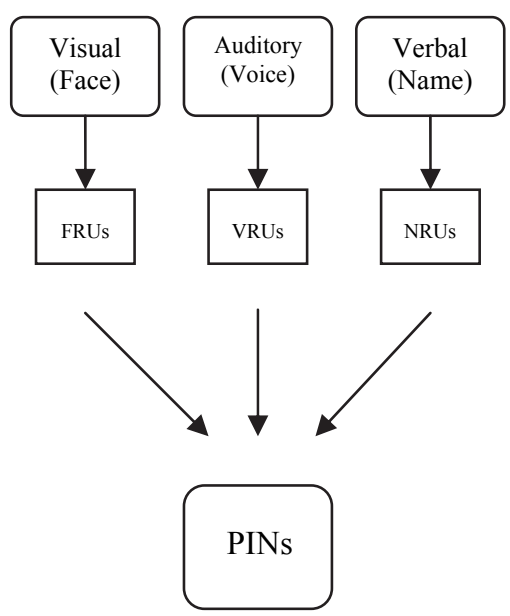

(Familiarity feelings)

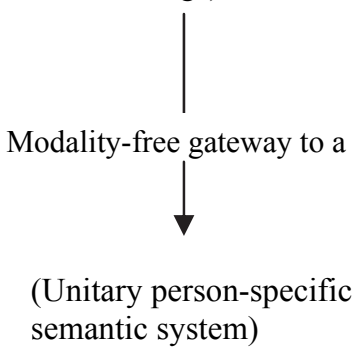

Fig. 1. Main differences between the original Bruce \& Young (1986) model and the subsequent, more complex models of familiar people recognition.

Figure 1 reports in a schematic manner the main differences existing between the Bruce and Young (1986) model and the following models (e.g. Burton et al., 1990) with respect to the locus of generation of familiarity feelings and to the relations between PINs and personspecific semantic information.

But even the Burton et al.'s (1990, 1999), Brédart et al.'s (1995) and Valentine et al.'s (1996) statement that information about people is stored in an amodal format in the person-specific 
semantic system is open to controversies, because some authors (e.g. Snowden et al., 2004; Gainotti et al., 2003 and 2010; Gainotti, 2007a and 2011) maintain that this information is stored in a different format at the hemispheric level, i.e. in a multisensory/pictorial format in the right hemisphere and in a verbally-coded format in the left hemisphere.

Coming back from these general models and controversies to the dominance of face recognition in the identification of famous (or personally familiar) people, it is necessary to clearly distinguish 'prosopagnosia' (a defect of face/people recognition, restricted to the visual modality) from multimodal disorders in familiar people recognition, but this distinction has not been systematically made in the literature, because many patients who showed a multimodal disorder in familiar people recognition have been described as affected by prosopagnosia. This failure to distinguish prosopagnosia from multimodal familiar people recognition disorders is probably due to the dominance of faces in the recognition of known people and can be observed both in anatomo-clinical observations and in group studies. To stress the frequency with which patients affected by a multimodal people recognition defect have been considered as instances of prosopagnosia, and to underline the anatomical locus of lesion that subsume the multimodal forms of familiar people recognition disorders, we will limit ourselves to quote two classical anatomo-clinical observations, and two recent group studies of patients affected by right temporal variant of fronto-temporal degeneration (Hodges, 2000; Snowden et al., 1996; Tyrrel et al., 1990). The first anatomo-clinical observation, originally reported by Bouduresque et al. (1979) and afterwards studied in more details by Sergent \& Poncet (1990), concerned a patient (M.me V.) who, after a Herpes Simples Encephalitis (HSE), complained of severe difficulties to recognize familiar people by face, in the absence of intellectual, memory, linguistic or visual defects.

The claim that M.me V's defective recognition of familiar people was not due to a subtle disorder of visual perception was documented by the fact that she showed no problems in the treatment of unknown faces during administration of a test similar to the Benton and Van Allen (1968) face matching test. Bouduresque et al. (1979) also noted that their patient repeatedly claimed being able to identify her family members, by hearing their voice, but that her performance was very poor when voice identification was investigated with an objective procedure. As for the lesion location, she showed on CT scan, a massive damage of the anterior parts of the right temporal lobe (RTL), in keeping with the usual localization of lesions caused by HSE (Gitelman et al., 2001).

The second anatomo-clinical observation concerned a man (LP) reported by De Renzi (1986) and De Renzi et al. (1987), who had also suffered from a previous HSE. This patient showed a widespread semantic disorder, but was unimpaired from the attentional, linguistic and visual point of view (including tests performed with unknown faces) and was considered as a case of 'associative prosopagnosia' (De Renzi et al.,1991), even if he also showed a multimodal defect of familiar people identification. As in the Bouduresque et al.'s (1979) patient, the anatomical lesion involved the antero-mesial parts of the temporal lobes, but this time with a left-sided prevalence. The two group studies relevant to the distinction between prosopagnosia and multimodal familiar people recognition disorders have been reported by Josephs et al. (2008) and by Chan et al. (2009). The first authors, starting from the description of a 'progressive prosopagnosia' in two SD patients (Evans et al., 1995; Joubert et al., 2003), tried to assess with the 'voxel-based morphometry' (VBM) the patterns of gray matter atrophy in SD patients with and without prosopagnosia. Results of this study showed that in SD patients with prosopagnosia atrophy mainly affects the antero-mesial 
parts of the RTL, whereas in those without prosopagnosia the lesion mainly involves the left temporal lobe. Chan et al. (2009), on the other hand, tried to identify the clinical profile associated with predominantly RTL atrophy and observed that prosopagnosia was reported by $60 \%$ of these patients. Note that, just as Bouduresque et al. (1979) and De Renzi (1986), also Josephs et al. (2008) were aware of having made an inappropriate use of the term 'prosopagnosia', because, contrary to what happens in real prosopagnosia, in their patients the person recognition defect was not confined to the visual (face) modality, but also concerned the voice and the name of the known person.

In any case, the just mentioned anatomo-clinical observations and the results of the group studies show that in patients with multimodal familiar people recognition disorders, the lesion lies outside the posterior temporo-occipital network involved in face processing. This network spans, indeed, from the inferior occipital areas ('Occipital Face Area/OFA of Gauthier et al., 2000) to the lateral portion of the mid-fusiform gyrus where is located the Face Fusiform Area (FFA/Kanwisher et al., 1997), whereas in patients showing a multimodal familiar people recognition disorder the lesion mainly involves the anterior parts of the TL.

\section{Patterns of familiar people recognition disorders observed in patients with right and left anterior temporal lesions}

Since in patients with multimodal familiar people recognition disorders the lesion can involve both the right (as in the Bouduresque et al.'s, 1979 patient) and the left anterior TL (as in the case reported by De Renzi, 1986), it became necessary to assess if familiar people recognition disorders are similar or different in patients with right and left TL lesions and to evaluate if these differences are relevant with respect to the controversies among theoretical models that we have summarized in the first part of the introduction. The first important contribution in this direction has been provided by Snowden et al. (2004), who have argued that a fine-grained investigation of the person-specific semantic impairment obtainable from visual (face) and verbal (name) stimuli in patients with degenerative lesions of the right and left TL could contribute: (a) to evaluate if different patterns of familiar people recognition disorders can be observed in patients with right and left TL lesions and (b) to clarify the debate concerning the 'unitary' (abstract-amodal) or 'non-unitary' (concretemultisensory vs verbally-coded) format of semantic representations.

One of the cornerstones of this debate turns, in fact, around the hypothesis that dissociations in access to the semantic representation through the visual and the verbal modalities may be due to the 'perceptual affordances' of objects, namely to the perceptual features that could "suggest" which actions can be performed with those objects (Norman, 1988), allowing 'privileged accessibility' from vision to part of the semantic representation (Caramazza et al., 1990). Snowden et al. (2004) reasoned that, since people's faces and names are arbitrary, the study of person-specific semantic information obtainable from visual (face) and verbal (name) stimuli in patients with degenerative lesions of the right and left TL could represent a potentially valuable means of addressing the unitary vs non-unitary semantic systems controversy, ruling out the possible influence of the perceptual affordances of objects. Results of their study showed that semantic information accessed through face and name are different according to the prevalent side of atrophy. Semantic dementia patients with predominantly left temporal lobe atrophy identified faces better than names and performed better on the picture than on the word version of the semantic memory 'Pyramids and Palm 
Trees' test (Howard \& Patterson, 1992), whereas patients with right temporal lobe atrophy showed the opposite pattern of performance. These data were considered as incompatible with a unitary abstract model of semantic memory. A problem with this study consisted of the fact that, due to the rarity of this disease, the number of patients reported by Snowden et al. (2004) was relatively small and that paired comparisons between patients with right and left TL atrophy did, therefore, seldom reach significance. Since studies of semantic dementia patients typically involve single case studies, we thought that a strategy allowing to further check the Snowden et al.'s (2004) hypothesis could consist in systematically reviewing all the published individual cases of patients with a prevalent damage to the anterior parts of the right or left TL, in whom disorders of person recognition were on the foreground. Results of our review (Gainotti, 2007a) confirmed the findings of Snowden et al. (2004) and offered data provided of theoretical significance, since they were consistent with the Bruce and Young (1986) model, and inconsistent with the alternative models of Burton et al. (1990 and 1999), Bredart et al. (1995) and Valentine et al. (1996), with respect both to the locus of generation of familiarity feelings and to the functions of the PINs.

As for the first point, two main findings suggested that familiarity judgements were generated at the level of the modality-specific recognition units rather than at the PINs level. The first was that familiarity judgements were much more impaired in right than in left TL patients and the second that in patients with RTL lesions familiarity defects were modalityspecific, concerning more famous faces than famous names. These findings suggested that familiarity feelings, being modality-specific, should be generated at the level of recognition units and in particular of the FRUs, that could be more represented in the RTL due to the major role played by the right hemisphere in face processing (De Renzi, 1986; De Renzi et al., 1994; Michel et al., 1989).

As for the second point, results of our review were inconsistent for two main reasons with the hypothesis assuming that PINs provide a modality-free gateway to a single system, where semantic information about people is stored in an amodal format. The first was that in patients with a RT damage the loss of person-specific semantic information, was clearly greater from face than from name. The second was that an important imbalance between the amount of person-specific information available from faces and names was also found in right and left TL patients who, showing intact or mildly impaired familiarity judgments, should have (according to the previously mentioned cognitive models) no defect at the PINs level.

A factor that could weaken the relevance of results obtained in our review, with respect to the models of familiar people recognition, was the Haslam et al.'s (2004) observation that in normal subjects both familiarity judgements and access to biographical information are more accurate in response to names than to faces. Now, since in studies considered in our review there were often no normative data, that considered separately familiarity judgement and biographical information obtainable from faces and from names, it was possible that the greater loss of familiarity feelings and of biographical information obtained from faces by RTL patients was in part due to this methodological pitfall. To check if differences observed in our review between patients with right and left anterior TL atrophy were due to the 'normal' differences about familiarity judgements and access to biographical information in response to names and faces reported by Haslam et al. (2004), we conducted a new research (Gainotti et al., 2010) in which we made use of two very well controlled normative studies, recently conducted by Bizzozero et al. (2005) and by Bizzozero, et al. (2007) on Italian participants. In the Bizzozero et al. (2005 and 2007) norms, the influence of age, education 
and gender on familiarity recognition and on person identification from faces and names had been controlled by means of covariate linear models, removing the effect of each variable and calculating from each subject's raw score the corresponding adjusted score. In a second step, the adjusted scores had been classified into five equivalent scores categories, ranging from 0 (= scores lower than the outer $5 \%$ inferential tolerance limits) to 4 (= scores higher than the median value of the sample). Furthermore, in the Bizzozero et al.'s (2005 and 2007) data, the semantic interviews aiming to assess the person identification were restricted to the faces and names correctly judged as familiar by the patient and therefore to people whose PINs should be unimpaired. Possible discrepancies between results obtained from faces and names with this procedure should, therefore, point to a different format of the semantic representation accessed through these different channels and could not be explained on the basis of methodological inconsistencies. The Bizzozero et al. (2005 and 2007) tests of face and name recognition and identification were administered to two patients, showing a selective mild difficulty of familiar people identification and naming due to a predominantly right and left TL atrophy, to see if the conclusions of our previous review were confirmed even with this highly controlled material. If the conclusions of our previous review were correct, the right TL patient should again show a greater impairment of familiarity feelings and of access to person-specific semantic information from faces, whereas, if results of our previous review were biased by a 'normal' advantage of names over faces we should observe in this patient no name advantage in familiarity judgment or access to person-specific semantic information. Data obtained in the right TL patient by Gainotti et al. (2010) confirmed the results of the previous review, since this patient showed: (1) a very impaired familiarity for faces, contrasting with a spared familiarity for names, indicating that familiarity judgments are generated at the level of modality-specific recognition units and not of a supramodal PIN; (2) a prevalent impairment of personspecific information available from faces rather than from names also for people that (being recognized as familiar from their face and name), should be normally represented at the PINs level.

\section{The format of person-specific semantic information}

Results of our previous review (Gainotti, 2007a) and behavioural data (Gainotti et al., 2010) obtained in a right TL patient, affected by a selective defect of familiar people identification, had a third implication, besides the fact of showing: (a) that familiarity feelings are generated at the level of modality-specific recognition units and (b) that PINs cannot be simply considered as a modality-free gateway to the person-specific semantic system, because they also suggested (c) that semantic information about people is stored in a different format at the level of the right and left temporal lobes. These data, therefore, confirmed the previous results of Snowden et al. (2004) who had shown that semantic dementia patients with predominantly right temporal lobe atrophy are more impaired with faces than with names, whereas patients with left TL atrophy show the opposite pattern of performance. Taken together, data obtained by Snowden et al. (2004) and our results strongly suggested that semantic representations of famous people are not represented in an 'amodal format' in both temporal lobes, but in a pictorial format in the right and in a verbal format in the left temporal lobe. Furthermore the Snowden et al.'s (2004) observations that semantic dementia patients with predominantly right temporal lobe atrophy perform worse on the picture than on the word version of the semantic memory 'Pyramids and Palm Trees' 
test (Howard \& Patterson, 1992), suggest that this different format is not limited the semantic representation of famous people, but also extends to other conceptual domains. This suggestion is supported by both behavioural and neuroimaging data.

Behavioural data in line with the assumption of a prevalent involvement of the left TL in verbal and of the right TL in pictorial aspects of conceptual knowledge, have been obtained by Damasio et al. (1996 and 2004) and Tranel et al. (1997) in patients with focal lesions of the left and right temporal lobes. Damasio et al. (1996 and 2004) showed that defective retrieval of words denoting entities from various conceptual domains (such as famous people, animals or artefacts) was associated with lesions encroaching upon different parts of the left temporal lobe, whereas Tranel et al. (1997) demonstrated that impaired recognition of pictures representing persons, animals or tools was associated with lesions of the homologous areas of the right temporal lobe. According to these authors, both the left and the right temporal lobes play a mediational role in concept retrieval, but in the left hemisphere the activation of the "word" intermediary region promotes the retrieval of lexical knowledge required for word production, whereas in the right hemisphere the recollection of the perceptual properties of a given stimulus promotes the concrete sensorimotor representation of knowledge pertaining to that object.

Other behavioural data consistent with the hypothesis of a different involvement of the left and right temporal lobes in verbal and pictorial aspects of conceptual knowledge have been obtained in SD patients by Ikeda et al. (2006). These authors tested 10 SD patients and 10 matched controls on an object recognition task in which they were invited to choose (from a four-item array) the picture representing "the same thing" as an object picture that they had just inspected and attempted to name. The target in the response array was never physically identical to the studied picture but differed from it for various aspects. The patients whose structural brain imaging revealed major right-temporal atrophy were more impaired than those with an asymmetric pattern characterised by predominant left-sided atrophy, showing that they had a selective defect in the retrieval of the pictorial properties of objects.

\subsection{Correlations between cognitive and neuroimaging data, studying person related and conceptual knowledge with verbal and pictorial material}

A different role of the right and left ATL has been documented by functional neuroimaging investigations that have taken into account different aspects of familiar people recognition or of conceptual knowledge. Thus, several authors have documented a prevalent activation of the right temporal lobe for famous faces (Ishai et al., 2005), for famous - contrasted with newly learned - faces (Leveroni et al., 2000), during association between faces and personspecific semantic information (Tsukiura et al., 2008) or during a semantic categorization task of famous faces (Brambati et al., 2010). On the other hand, Tsukiura et al. (2008) have shown that the left ATL may mediate associations between names and person-related semantic information and similar results have been obtained by Brambati et al. (2010), who have shown an increased activation of the left anterior TL when subjects were asked to determine whether a stimulus photograph matched with the label of a profession category. Consistent with these results obtained studying different aspects of familiar people recognition are results of investigations which have assessed the correlations between neuroimaging data and conceptual impairment in the verbal and pictorial modality.

Thus, Acres et al. (2009) and Butler et al. (2009), evaluating conceptual knowledge with verbal and pictorial material, and the severity of temporal lobe atrophy with voxel-based measures, have shown that verbal semantic defects are on the foreground when the atrophy 
mainly affects the left temporal lobe, whereas non-verbal conceptual disorders tend to prevail when the right inferior temporal structures are preferentially disrupted. Similar data have been recently obtained by Mion et al. (2010), who examined with FDG-PET the neural correlates of verbal and non-verbal semantic measures in SD. The semantic verbal task was a picture naming task, whereas the non-verbal semantic task was the 'Camel and Cactus test' (Bozeat et al., 2000), similar to the pictorial version of the semantic memory 'Pyramids and Palm Trees' test (Howard \& Patterson, 1992). Regions of interest (ROIs) were the left and right anterior fusiform gyri and the temporal poles. The left anterior fusiform activity predicted performance on the verbal semantic tasks, whereas the right anterior fusiform metabolism predicted performance on the non-verbal semantic task. Furthermore, an additional behavioural study, performed on a wider cohort of SD patients, confirmed that patients with more extensive right TL atrophy are significantly more impaired on tests of non-verbal semantics.

\section{Concluding remarks on the implications of these data for models of familiar people recognition}

We will conclude this chapter by reporting in a schematic manner in Figure 2 the implications that data concerning: (a) the patterns of familiar people recognition shown by right and left TL patients and (b) the different format of (person-specific or conceptual) knowledge represented in the right and left temporal lobes could have for models of familiar people recognition.

Two main conclusions are suggested by results of investigations surveyed in the previous sections of this chapter and summarized in Figure 2. The first is that results concerning (a) the locus of generation of familiarity feelings, (b) the relationships between PINs and person-specific semantic knowledge and (c) the format of this kind of knowledge are much more consistent with the simpler and older model of Bruce and Young's (1986) than with the more recent and complex models of familiar people recognition proposed by Burton et al. (1990, 1999), Brédart et al. (1995) and Valentine et al. (1996). The second is that, to give a plausible account of data obtained in brain-damaged patients, these models cannot ignore some basic inter-hemispheric differences, such as the critical role of the right hemisphere in the generation of face familiarity feelings and the different format of person-specific semantic knowledge at the level of the right and left hemisphere.

Both these issues have been thoroughly discussed in previous reviews (Gainotti, 2007b and 2011) and will be only shortly considered here as two sides of a unitary phenomenon, namely the more primitive (sensori-motor) organization of the right hemisphere and the more complex, language-mediated organization of the left hemisphere.

Within this context, it is possible to assume that the early familiarity feelings may be automatically elicited through a right-hemisphere subcortical route, allowing a first, unconscious, global recognition of familiar faces and fostering the subsequent distinction of known faces (unconsciously detected) from unfamiliar faces.

From the theoretical point of view, this possibility has been suggested by De Haan et al. (1991) with the following expression: 'When a FRU is activated it will signal that the face is familiar and instigate the retrieval of semantic knowledge concerning the bearer of the face'. Within the same framework, it seems logical to assume that, far from being represented in an abstract amodal format, every kind of person-specific and conceptual knowledge may consist of a more primitive perceptual-motor knowledge (more represented in the right 
hemisphere) and of a more complex language-mediated and language-structured knowledge, more represented in the left hemisphere. From this point of view, the prevalent impairment of person-specific information available from faces, that we have documented in patients with a right TL atrophy, could be considered as the most impressive manifestation of the disruption of the multi-sensory/pictorial knowledge that seems typical of the right hemisphere.

\section{RIGHT Hemisphere}

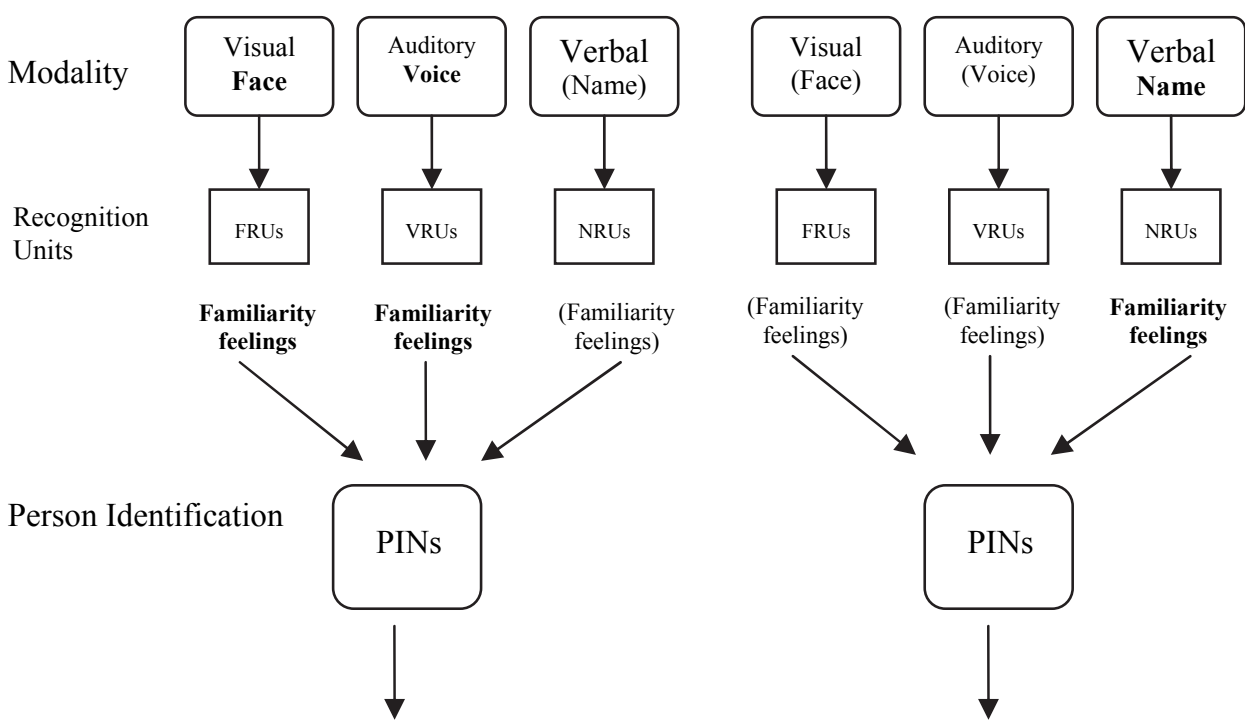

Person-specific semantic knowledge (Temporal poles)
Convergence zones of semantic knowledge $\begin{array}{cc}\text { mainly based upon } & \text { mainly based upon } \\ \text { visual and auditory } & \text { verbally coded } \\ \text { information } & \text { information }\end{array}$

Fig. 2. Main differences between the familiar people recognition disorders shown by patients with right and left anterior temporal lesions. In bold are reported the modalities of people recognition and the corresponding familiarity feelings that are more represented at the level of the right and left hemisphere.

\section{References}

Acres, K., Taylor, K.I., Moss, H.E., Stamatakis, E.A. \& Tyler, L.K. (2009). Complementary hemispheric asymmetries in object naming and recognition: a voxel-based correlational study. Neuropsychologia, Vol.47, No.8-9, (July 2009), pp. 836-843, ISSN 0028-3932

Benton, A.L. \& Van Allen, M.W. (1968). Impairment in facial recognition in patients with cerebral disease. Cortex, Vol.4, No.4, pp. 344-358, ISSN: 0010-9452 
Bizzozero, I., Ferrari, F., Bozzoli, S., Saetti, M.C. \& Spinnler, H. (2005). Who is who: Italian norms for visual recognition and identification of celebrities. Neurological Sciences, Vol.26, No.2, (June 2005), pp. 95-107, ISSN 15901874

Bizzozero, I., Lucchelli, F., Bozzoli, S., Saetti, M.C. \& Spinnler, H. (2007). "What do you know about Ho Chi Minh?" Italian norms of proper name comprehension. Neurological Sciences, Vol.28, No.1, (March 2007), pp. 16-30, ISSN 1590-1874

Bodamer, J. (1947). Die Prosop-Agnosie. Archiv für Psychiatrie und Nervenkrankheiten, Vol. 179, No. (1-2), pp. 6-53

Boudouresques, J., Poncet, M., Cherif, A.A. \& Balzamo, M. (1979). Agnosia for faces: evidence of functional disorganization of a certain type of recognition of objects in the physical world. Bulletin de l'Académie Nationale de Medecine, Vol.163, No.7, (October 1979), pp. 695-702

Bozeat, S., Lambon Ralph, M.A., Patterson, K., Garrard, P. \& Hodges, J.R. (2000). Non-verbal semantic impairment in semantic dementia. Neuropsychologia, Vol.38, No.9, pp. 1207-15, ISSN 0028-3932

Brambati SM, Benoit S, Monetta L, Belleville S, Joubert S. (2010) The role of the left anterior temporal lobe in the semantic processing of famous faces. Neuroimage, Vol.1, No.53(2), (November 2010), pp. 674-681, ISSN 1053-8119

Brédart, S., Valentine, T., Caldor, A. \& Gassi, L. (1995). An interactive activation model of face naming. The Quarterly Journal of Experimental Psychology, Vol.48, No.2, (May 1995), pp. 466-486, ISSN 0272-4987

Bruce, V. \& Young A.W. (1986). Understanding face recognition. British Journal of Psychology, Vol.77, No.3, (August 1986), pp. 305-327

Burton, A.M., Bruce, V. \& Hancock, P.J.B. (1999). From pixels to people: a model of familiar face recognition. Cognitive Science, Vol.23, No.1, (January 1999), pp. 1-31

Burton, A.M., Bruce, V. \& Johnston, R.A., 1990. Understanding face recognition with an interactive activation model. British Journal of Psychology, Vol.81, No.3, (August 1990), pp. 361-381, ISSN 2044-8295

Butler, C.R., Bramati, S.M., Miller, B.L. \& Gorno-Tempini, M.L. (2009). The neural correlates of verbal and nonverbal semantic processing deficits in neurodegenerative disease. Cognitive and Behavioral Neurology, Vol.22, No.2, (June 2009), pp. 73-80, ISSN 1543-3633

Caramazza, A., Hillis, A., Rapp, B.C. \& Romani, C. (1990). The multiple semantic hypothesis: Multiple confusions? Cognitive Neuropsychology, Vol.7, No.3, pp. 161189, ISSN 1464-0627

Chan, D., Anderson, V., Pijnenburg, Y., Whitwell, J., Barnes, J., Scahill, R., Stevens, J.M., Barkhof, F., Scheltens, P., Rossor, M.N. \& Fox, N.C. (2009). The clinical profile of right temporal lobe atrophy. Brain, Vol.132(Pt 5), (May 2009), pp.1287-98, ISSN 0006-8950

Damasio, H., Grabowski, T.J., Tranel, D., Hichwa \& R.D., Damasio, A.R. (1996). A neural basis for lexical retrieval. Nature, Vol.11, No.380(6574), (April 1996), pp. 499-505 ISSN: 0028-0836

Damasio, H., Tranel, D., Grabowski, T.J., Adolphs, R. \& Damasio, A.R. (2004). Neural systems behind word and concept retrieval. Cognition, Vol.92, No. 1-2, (May-June 2004), pp. 179-229, ISSN 0010-0277

De Haan, E.H., Young, A.W., Newcombe, F., (1991). A dissociation between sense of familiarity and access to semantic information concerning familiar people. European Journal of Cognitive Psychology, Vol.3, No.1, 51-67, ISSN 2044-5911 
De Renzi, E. (1986). Current issues in prosopagnosia. In: Aspects of face processing, Ellis, H.D., Jeeves, M.A., Newcombe, F. and Young, A.W. (Eds.) 243-252, NATO ASI series, Martinus Nijhoff, Dordrecht

De Renzi, E., Liotti, M., \& Nichelli, P. (1987). Semantic amnesia with preservation of autobiographic memory: A case report. Cortex, Vol.23, No.4, (December 1987), pp.575-597, ISSN: 0010-9452

De Renzi, E., Faglioni, P., Grossi, D. \& Nichelli, P. (1991). Apperceptive and associative forms of prosopagnosia. Cortex, Vol.27, No.2, (June 1991), pp. 213-221, ISSN: 0010-9452

De Renzi, E., Perani, D., Carlesimo, G.A., Silveri, M.C. \& Fazio, F. (1994). Prosopagnosia can be associated with damage confined to the right hemisphere. An MRI and PET study and a review of the literature. Neuropsychologia, Vol.32, No.8, (August 1994), pp. 893-902, ISSN 0028-3932

Evans, J.J., Heggs, A.J., Antoun, N. \& Hodges J.R. (1995). Progressive prosopagnosia associated with selective right temporal lobe atrophy. A new syndrome? Brain, Vol.118, Pt.1, (February 1995), pp. 1-13, ISSN 0006-8950

Gainotti, G. (2007a). Different patterns of famous people recognition disorders in patients with right and left anterior temporal lesions: A systematic review. Neuropsychologia, Vol.45, No.8, (April 2007), pp. 1591-1607, ISSN 0028-3932

Gainotti, G. (2007b). Face familiarity feelings, the right temporal lobe and the possible underlying neural mechanisms. Brain Research Reviews, Vol.56, No.1, (November 2007), pp. 214-235, ISSN 0165-0173

Gainotti, G. (2011). The format of conceptual representations disrupted in semantic dementia. (Submitted)

Gainotti, G., Barbier, A. \& Marra, C. (2003). Slowly progressive defect in recognition of familiar people in a patient with right anterior temporal atrophy. Brain, Vol.126, Pt.4, (April 2003), pp. 792-803, ISSN 0006-8950

Gainotti, G., Ferraccioli, M. \& Marra C. (2010). The relation between person identity nodes, familiarity judgment and biographical information. Evidence from two patients with right and left anterior temporal atrophy. Brain Research, Vol.1307, No.11, (January 2010), pp. 103-114, ISSN: 00068993

Gauthier, I., Tarr, M.J., Moylan, J., Skudlarski, P., Gore, J.C. \& Anderson, A.W. (2000). The fusiform "face area" is part of a network that processes faces at the individual level. Journal of Cognitive Neuroscience, Vol.12, No.3, (May 2000), pp. 495-504, ISSN 0898929X

Gitelman, D., Ashburner, J., Friston, K., Tyler, L. K. \& Price, C. (2001). Voxel-based morphometry of herpes simplex encephalitis. Neuroimage, Vol.13, No.4, (April 2001), pp. 623-631, ISSN 1053-8119

Haslam, C., Kay, J., Hanley, J.R. \& Lyons, F. (2004). Biographical knowledge: modality specific or modality-neutral? Cortex, Vol.40, No.3, (June 2004), pp. 451-466, ISSN 0010-9452

Hodges J.R. (2000) Pick's disease: It's relationship to semantic dementia, progressive aphasia and frontotemporal dementia. In: Dementia, J. O’Brien, D. Ames, A. Burns, (Ed.), 741-758, Arnold, London

Howard, D. \& Patterson, K. (1992). Pyramids and Palm Trees: access from pictures and words. Thames Valley Test Company, Bury St Edmunds, UK

Ikeda, M., Patterson, K., Graham, K.S., Lambon Ralph, M.A. \& Hodges, J.R. (2006). A horse of a different colour: do patients with semantic dementia recognise different versions of the same object as the same? Neuropsychologia, Vol.44, No.4, pp. 566-575, ISSN 0028-3932 
Ishai, A., Schmidt, C.,F. \& Boesinger, P. (2005). Face perception is mediated by a distributed cortical network. Brain Research Bulletin, Vol.67, No.1-2, (September 2005), pp. 87-93, ISSN 0361-9230

Josephs, K.A., Whitwell, J.L., Vemuri, P., Senjem, M.L., Boeve, B.F., Knopman, D.S., Smith, G.E., Ivnik, R.J., Petersen, R.C. \& Jack, C.R. Jr. (2008). The anatomic correlate of prosopagnosia in semantic dementia. Neurology, Vol.71, No.20, (November 2008), pp. 1628-33, ISSN 0028-3878

Joubert, S., Felician, O., Barbeau, E., Sontheimer, A., Guedj, E., Caccaldi, M. \& Poncet, M. (2003). Impaired configurational processing in a case of progressive psosopagnosia associated with predominant right temporal lobe atrophy. Brain, Vol.126, Pt.11, (November 2003), pp. 2357-50, ISSN 0006-8950

Kanwisher, N., McDermott, J. \& Chun, M.M. (1997). The fusiform face area: a module in human extrastriate cortex specialized for face perception. Journal of Neuroscience, Vol.17, No.11, (June 1997), pp. 4302-431, ISSN 0270-6474

Leveroni, C.L., Seidenberg M., Mayer A.R., Mead L.A., Binder, J.R.,Rao, S.M., 2000. Neural systems underlying the recognition of familiar and newly learned faces. Journal of Neuroscience, Vol.20, No.2, (January 2000), pp. 878-886, ISSN 0270-6474

Michel, F., Poncet, M. \& Signoret, J.L. (1989). Les lésions responsables de la prosopagnosie sont-elles toujours bilatérales? Revue Neurologique, Vol.146, Paris, pp. 764-770, ISSN 0035-3787

Mion, M., Patterson, K., Acosta-Cabronero, J., Pengas, G., Izquierdo-Garcia, D., Hong, Y.T., Fryer, T.D., Williams, G.B., Hodges, J.R. \& Nestor, P.J. (2010). What the left and right anterior fusiform gyri tell us about semantic memory. Brain, Vol.133, No.11, (November 2010), pp. 3256-3268, ISSN 0006-8950

Norman D. A. (1988). The Psychology of Everyday Things. New York, Basic Books.

Sergent J. \& Poncet M. (1990). From covert to overt recognition of faces in a prosopagnosic patient. Brain, Vol.113, Pt.4, (August 1990), pp. 989-1004, ISSN 0006-8950

Snowden, J.S., Neary D. \& Mann D.M.A. (1996) Fronto-temporal lobar degeneration: frontotemporal dementia, progressive aphasia,semantic dementia. Churchill Livingstone, New York

Snowden, J.S., Thompson, J.C., Neary, D. (2004). Knowledge of famous faces and names in semantic dementia. Brain, Vol.127, Pt.4, (April 2004), pp. 860-872, ISSN 0006-8950

Tranel, D., Damasio, H. \& Damasio, AR. (1997). A neural basis for the retrieval of conceptual knowledge. Neuropsychologia, Vol.35, No.10, (October 1997), pp. 1319-1327, ISSN 0028-3932

Tsukiura, T., Suzuki, C., ShigemuneY. \& Mokizuki-Kawai, H. (2008). Differential contribution of the anterior temporal and medio temporal lobe to the retrieval of memory for person identity information. Human Brain Mapping, Vol.29, No.12, (December 2008), pp. 1343-54, ISSN 1065-9471

Tyrrel, P.J., Warrington, E.K., Frackowiak, R.S.J. \& Rossor, M.N. (1990). Progressive degeneration of the right temporal lobe studies with positron emission tomography. Journal of Neurology, Neurosurgery and Psychiatry, Vol.53, No.12, (December 1990), pp. 1046-1050, ISSN: 00223050

Valentine, T., Brennen, T., Bredart, S., (1996). The cognitive psychology of proper names. Routledge, London

Young, A.W. \& Burton, A.M. (1999). Simulating face recognition: implications for modelling cognition. Cognitive Neuropsychology, Vol.16, No.1, (February 1999), pp. 1-48, ISSN: 1464-0627 


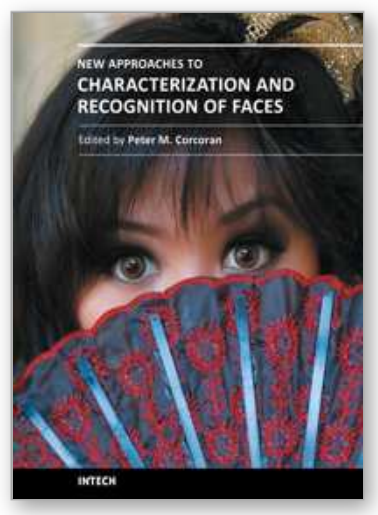

\author{
New Approaches to Characterization and Recognition of Faces \\ Edited by Dr. Peter Corcoran
}

ISBN 978-953-307-515-0

Hard cover, 252 pages

Publisher InTech

Published online 01, August, 2011

Published in print edition August, 2011

As a baby, one of our earliest stimuli is that of human faces. We rapidly learn to identify, characterize and eventually distinguish those who are near and dear to us. We accept face recognition later as an everyday ability. We realize the complexity of the underlying problem only when we attempt to duplicate this skill in a computer vision system. This book is arranged around a number of clustered themes covering different aspects of face recognition. The first section presents an architecture for face recognition based on Hidden Markov Models; it is followed by an article on coding methods. The next section is devoted to 3D methods of face recognition and is followed by a section covering various aspects and techniques in video. Next short section is devoted to the characterization and detection of features in faces. Finally, you can find an article on the human perception of faces and how different neurological or psychological disorders can affect this.

\title{
How to reference
}

In order to correctly reference this scholarly work, feel free to copy and paste the following:

Guido Gainotti, Monica Ferraccioli and Camillo Marra (2011). The Effects of Right/Left Temporal Lobe Lesions on the Recognition of Familiar Faces, New Approaches to Characterization and Recognition of Faces, Dr. Peter Corcoran (Ed.), ISBN: 978-953-307-515-0, InTech, Available from:

http://www.intechopen.com/books/new-approaches-to-characterization-and-recognition-of-faces/the-effects-ofright-left-temporal-lobe-lesions-on-the-recognition-of-familiar-faces

\section{INTECH}

open science | open minds

\section{InTech Europe}

University Campus STeP Ri

Slavka Krautzeka 83/A

51000 Rijeka, Croatia

Phone: +385 (51) 770447

Fax: +385 (51) 686166

www.intechopen.com

\section{InTech China}

Unit 405, Office Block, Hotel Equatorial Shanghai

No.65, Yan An Road (West), Shanghai, 200040, China

中国上海市延安西路65号上海国际贵都大饭店办公楼 405 单元

Phone: +86-21-62489820

Fax: $+86-21-62489821$ 
(C) 2011 The Author(s). Licensee IntechOpen. This chapter is distributed under the terms of the Creative Commons Attribution-NonCommercialShareAlike-3.0 License, which permits use, distribution and reproduction for non-commercial purposes, provided the original is properly cited and derivative works building on this content are distributed under the same license. 